Encontro Nacional de

Economia Industrial e Inovação

\title{
OFERTA E DEMANDA DE CAPACITAÇÃO PARA SERVIÇOS EMPRESARIAIS INTENSIVOS EM CONHECIMENTO NO ESTADO DO RIO DE JANEIRO
}

\author{
Renata Lèbre La Rovere* \\ Guilherme de Oliveira Santos** \\ Elisama Silva de Almeida***
}

\begin{abstract}
Resumo: Os Serviços Empresariais Intensivos em Conhecimento (Knowledge Intensive Business Services [KIBS]) envolvem atividades econômicas que têm como objetivo a criação, acumulação ou disseminação de conhecimento, podendo contribuir significativamente para a geração de valor, devido ao seu potencial inovador. Este artigo tem como objetivo realizar um diagnóstico das condições de capacitação para Serviços Empresariais Intensivos em Conhecimento relevantes para a economia do Estado do Rio de Janeiro e refletir de que forma tais condições afetam as possibilidades de desenvolvimento de inovações. A metodologia da pesquisa se estruturou em cinco etapas: 1) revisão bibliográfica sobre KIBS através de pesquisa no Portal de Periódicos CAPES; 2) seleção dos segmentos mais importantes destes serviços para o Estado do Rio de Janeiro usando a Classificação Nacional das Atividades Econômicas (CNAE/IBGE); 3) Cálculo, para cada um destes segmentos dos Quocientes Locacionais para todos os municípios do Estado a fim de identificar as demandas por capacitação; 4) Mapeamento das ofertas de capacitação em cursos de nível técnico, superior e pós-graduação lato e stricto senso para os segmentos que se mostraram relevantes no Estado; 5) cruzamento entre oferta e demanda para identificação dos potenciais ambientes de inovação no ERJ. Os resultados sugerem que grande parte da oferta e demanda de capacitação por KIBS no ERJ está concentrada na sua região metropolitana, o que impõe limites à contribuição destes serviços para o desenvolvimento de ambientes de inovação.
\end{abstract}

Palavras-Chave: Serviços Empresariais Intensivos em Conhecimento. Ambientes de Inovação. Capacitação. Estado do Rio de Janeiro.

Abstract: Knowledge Intensive Business Services (KIBS) involve activities that have the purpose of creating, appropriating or disseminating knowledge, and may be important for value generation, due to their innovative potential. This article has the main purpose of diagnosing the relevant training conditions of Knowledge Intensive Business Services for the economy of the State of Rio de Janeiro (SRJ). Furthermore, this article will analyze how these conditions affect the possibilities of development of innovation. The research methodology of this article was structured in five steps: 1) bibliographic review on KIBS through research in the Portal of CAPES Journals; 2) selection of the most important segments of these services for the State of Rio de Janeiro using the National Classification of Economic Activities (CNAE / IBGE); 3) Calculations of each of these segments using Locational Quotients of all the municipalities of the State, in order to identify demands for capacity building; 4) Mapping of training courses in technical, higher and postgraduate education for segments that were relevant in the State; 5) cross-reference between supply and demand to identify potential innovation environments in the SRJ. The results suggest that a large part of the supply and demand of training by KIBS in the SRJ is concentrated in its metropolitan region, which imposes limitations to the contribution of these services to development of innovation environments.

Keywords: Knowledge Intensive Business Services. Innovation Environments. Training. State of Rio de Janeiro.

Área Temática: 3.3. Estratégias Empresariais; 4.2. Economias Regionais e Urbanas.

JEL: L84; O18; O30; R12

\footnotetext{
* Doutora pela Université Paris 7. Professora do Instituto de Economia da Universidade Federal do Rio de Janeiro. Contato: renata@ie.ufrj.br

** Doutorando no Programa de Pós Graduação em Políticas Públicas, Estratégias e Desenvolvimento (PPED) do Instituto de Economia da UFRJ (IE/UFRJ) e Bolsista CAPES. Contato: guilhermedeoliveirasantos.gos@gmail.com

*** Graduanda em Ciências Econômicas na Universidade Federal do Rio de Janeiro e Bolsista de Iniciação Científica do CNPq. Contato: elisamasilva18@ hotmail.com
} 


\section{INTRODUÇÃO}

A trajetória da economia do Estado do Rio de Janeiro (ERJ) nas últimas décadas é marcada por ciclos que intercalam crises profundas com períodos de bonança econômica alavancados pela atração de grandes investimentos. A questão chave é que os momentos de prosperidade não conseguem criar lastros sólidos para que o estado construa uma trajetória de desenvolvimento econômico sustentável, ficando a mercê de mudanças conjunturais que fogem ao seu controle. Recentemente, apostou-se em uma "inflexão econômica positiva" (Santos, 2002; Natal, 2004) alicerçada nos expressivos investimentos em torno da cadeia do Petróleo e Gás (P\&G), siderurgia, metal-mecânica, automobilística e infraestrutura urbana (Hasenclever et al., 2012). No entanto, o que se observou foi uma forte especialização da economia fluminense ao redor da indústria extrativa e perdas significativas em quase todos os setores da indústria de transformação. Ao mesmo tempo, o setor de serviços fluminense se distingue por serviços de baixo valor agregado, sendo dominado por serviços prestados às famílias, a despeito do potencial que o estado possui em desenvolver serviços mais dinâmicos em virtude da qualificação de sua mão de obra. Este quadro de baixo dinamismo econômico fica mais evidente ao considerar a fraca integração territorial da Região Metropolitana com o interior do estado, que contribuiu para gerar uma "estrutura produtiva oca" (Sobral, 2012; 2017).

A reversão desta trajetória passa pelo estímulo à inovação e sua difusão no conjunto da economia fluminense, elemento crucial para a diversificação econômica e, consequentemente, redução da dependência da cadeia de Petróleo e Gás e aumento da competitividade das firmas localizadas no estado. Neste contexto, destacam-se os Serviços Empresariais Intensivos em Conhecimento (Knowledge Intensive Business Services - KIBS), assim como desenvolvimento de software, serviços de engenharia e arquitetura, consultoria gerencial e serviços de $\mathrm{P} \& \mathrm{D}$, que tem alto potencial inovativo e são capazes de disseminar conhecimento e estimular a inovação entre diferentes setores. Além de possuírem maior valor agregado, tais serviços são decisivos para o desenvolvimento industrial. Cabe, portanto, investigar se o ERJ tem condições de desenvolver KIBS como forma de diversificação das suas atividades econômicas.

As condições de desenvolvimento de KIBS podem ser analisadas sob o prisma da capacitação. Por um lado, podemos supor que concentrações de atividades econômicas classificadas como KIBS são uma medida aproximada da demanda por capacitação nestes serviços. Por outro lado, podemos supor que o número de egressos do ensino superior no ERJ é uma medida aproximada da oferta destes serviços. $\mathrm{O}$ objetivo deste artigo, portanto, é realizar um diagnóstico das condições de capacitação para Serviços Empresariais Intensivos em Conhecimento relevantes para a economia fluminense e refletir de que forma estas condições de capacitação afetam as possibilidades de desenvolvimento de inovações.

A metodologia da pesquisa que fundamenta este artigo se dividiu em cinco etapas. Em primeiro lugar foi realizada uma revisão bibliográfica sobre KIBS e sua relação com a inovação através de uma pesquisa no Portal de Periódicos da CAPES. Em seguida foi feita a seleção dos segmentos mais importantes destes serviços para o ERJ utilizando a Classificação Nacional das Atividades Econômicas (CNAE/IBGE). Na terceira etapa foram calculados para cada um destes segmentos os Quocientes Locacionais e índices de relevância setorial e municipal para todos os municípios do estado e calculados os percentuais de empregados com nível superior completo e incompleto no ERJ e nos municípios, com o objetivo de identificar as demandas por capacitação nas diferentes macrorregiões Posteriormente, foi feito o mapeamento da oferta de capacitação em nível superior para os segmentos que se mostraram relevantes para o estado. No último estágio foi realizado o cruzamento entre oferta e demanda por capacitação a fim de identificar potenciais ambientes de inovação no ERJ. Os resultados sugerem que grande parte da oferta e demanda de capacitação por KIBS no ERJ está concentrada na capital e na região metropolitana, o que impõe limites à contribuição destes serviços para o desenvolvimento de ambientes de inovação no ERJ.

O artigo está dividido em cinco seções além desta introdução. A seção 2 sintetiza o contexto da economia do Estado do Rio de Janeiro nas últimas décadas. A terceira seção traz o Referencial Teórico sobre Serviços Empresariais intensivos em Conhecimento, suas principais definições, tipologias e classificações e sua relação com a inovação. A quarta seção detalha todas as etapas da metodologia. A seção 5 apresenta os principais resultados encontrados, incluindo as concentrações econômicas encontradas, a formação 
ofertada nas macrorregiões do estado para cada segmento e o cruzamento entre oferta e demanda de capacitação nas macrorregiões para os KIBS relevantes no estado. A última seção apresenta as considerações finais do estudo.

\section{CONTEXTO DA ECONOMIA DO ESTADO DO RIO DE JANEIRO NAS ÚLTIMAS DÉCADAS}

A economia do Estado do Rio de Janeiro (ERJ) passou por sucessivas crises na segunda metade do século XX, levando a um declínio de sua importância em relação ao contexto nacional. Este processo foi iniciado com a transferência da capital para Brasília (1961) e, posteriormente, com a fusão dos Estados da Guanabara e do Rio de Janeiro (1974), tendo como ápice os anos 1980, marcados por um declínio expressivo da produção industrial na Região Metropolitana. Nos anos 1990 este quadro começa a ser revertido a partir da descoberta das maiores reservas de petróleo do país na bacia de Campos dos Goytacazes, no Norte Fluminense, atraindo volumosos investimentos para a região com rebatimentos para o resto do estado, em áreas como petroquímica, indústria naval, siderurgia e metalurgia, e mais recentemente investimentos em infraestrutura urbana, rodovias e transporte público (La Rovere e Paranhos, 2011; Hasenclever et al., 2012; Sobral 2012; 2013; 2017).

A conjugação de grandes fluxos de investimento e do surgimento de fronteiras de expansão no interior levou muitos autores a apostarem em uma "inflexão econômica positiva" (Santos, 2002; Natal, 2004) para o estado, diagnóstico que não se comprovou nos anos seguintes. A economia do Petróleo e Gás conquistou um peso desproporcional na economia do ERJ (Marcellino, 2014; Britto et al., 2015), que se tornou fortemente especializada e presa a uma armadilha de baixo dinamismo econômico. O avanço espetacular da indústria extrativa, contudo, contrastou com as perdas significativas observadas em quase todos os setores da indústria de transformação, indicando uma desindustrialização relativa (Sobral, 2012; 2013). Paralelamente, o setor de serviços fluminense se distingue por serviços de baixo valor agregado, sendo dominado por serviços prestados às famílias, a despeito da capacidade que o estado possui para desenvolver serviços dinâmicos, essenciais para o desenvolvimento industrial, dado o elevado grau de escolaridade de sua mão de obra (Hasenclever et al., 2012; Osório, 2014).

Além disso, a fraca integração territorial da Região Metropolitana do Rio de Janeiro (RMRJ) com o interior do estado contribuiu para a desintegração do tecido produtivo, e, consequentemente, gerou uma "estrutura produtiva oca" (Sobral, 2013; 2017). Por essa razão, os grandes investimentos que fluíram para o ERJ nos últimos anos encontraram barreiras logísticas e tecnológicas para impulsionar a integração de cadeias produtivas ancoradas na base industrial relativamente sofisticada que ainda possui o Rio de Janeiro, e integrá-la com outros estados, sobretudo São Paulo (Hasenclever et al., 2012; Sobral 2013). Neste sentido, a economia fluminense tornou-se cada vez mais vulnerável aos efeitos negativos de conjunturas adversas. A despeito deste quadro adverso, o ERJ possui potencialidades para desenvolver uma trajetória de desenvolvimento econômico sustentável, baseada em inovação.

Por um lado, o Estado do Rio de Janeiro possui um conjunto expressivo de organizações e instituições voltadas à geração de conhecimento científico-tecnológico, com destaque para importantes universidades, institutos de pesquisa públicos e privados, e centros de P\&D de grandes empresas (Porto et al., 2012). Por outro lado, apesar da perda de dinamismo recente, o ERJ conserva uma base industrial relativamente complexa. Apesar de sua frágil integração territorial e consequente esgarçamento do seu tecido produtivo, incapaz de constituir uma integração produtiva qualificada, o peso da indústria fluminense a nível nacional ainda é significativa. Além da cadeia do P\&G, o Rio de Janeiro destaca-se também em setores como a metalurgia básica, metal-mecânica, farmacêutica, bebidas e construção naval (La Rovere et al., 2015); além de ter potencial nos setores de tecnologia da informação, produção de automóveis e economia criativa (FIRJAN, 2014). Desse modo, o estímulo à inovação e sua difusão no conjunto da economia fluminense são elementos cruciais para a diversificação da economia, e a consequente redução de sua dependência do setor de Petróleo e Gás, bem como pré-requisitos para que as firmas localizadas no estado aumentem o valor de sua produção e se tornem mais competitivas tanto nacional como internacionalmente. 
Neste contexto, os serviços intensivos em conhecimento, tais como desenvolvimento de software, serviços de engenharia e arquitetura, consultoria gerencial e serviços de P\&D podem desempenhar um papel chave neste processo, uma vez que os mesmos cada vez mais são reconhecidos como tendo alto potencial de inovação e capacidade de difundir conhecimento e estimular a inovação entre diferentes setores, contribuindo assim para o aumento da geração de valor na economia. Em particular, destacam-se os serviços intensivos em conhecimento prestados às empresas (KIBS), que possuem maior valor agregado e são decisivos para o desenvolvimento industrial. Apesar do potencial de desenvolvimento de tais serviços, um levantamento feito por Guimarães e Meirelles (2014) dos KIBS baseados em tecnologia no Brasil mostrou que o ERJ não apresenta um número expressivo de concentrações econômicas destas atividades. $\mathrm{Na}$ próxima seção discutiremos as definições, tipologias e classificações dos serviços empresariais intensivos em conhecimento.

\section{O SETOR DE SERVIÇOS E OS SERVIÇOS EMPRESARIAIS INTENSIVOS EM CONHECIMENTO - DEFINIÇÕES, TIPOLOGIAS E CLASSIFICAÇÕES}

\subsection{Principais características do Setor de Serviços}

Historicamente marginalizado nos estudos de economia tanto no Brasil quanto em outros países, o setor de serviços vem tornando-se alvo crescente de atenção nas últimas décadas em virtude do aumento de sua participação no emprego e no valor agregado (Kubota, 2006; 2009). Segundo Torres-Freire (2006), a partir dos anos 1970 certos fatores contribuíram para a expansão das atividades de serviços, com destaque para a crescente divisão técnica do trabalho, a progressiva concentração de capital, a expansão de mercados, o desenvolvimento das tecnologias da informação e as mudanças no ambiente institucional. Neste contexto, a flexibilização dos processos produtivos e dos mercados ampliou a complexidade das firmas e fez crescer a demanda por serviços. Complementarmente, Kon (1999) sinaliza que o avanço do processo de globalização as atividades econômicas nas últimas três décadas também impulsionou o crescimento do setor de serviços, especialmente os serviços prestados para as empresas multinacionais e transnacionais.

$\mathrm{Na}$ literatura é possível encontrar diversas definições para o termo "serviços" (p. ex., Hill, 1977; Metcalfe e Miles, 1997; Czarnitzki e Spielkamp, 2003; Kon, 2004; Abdal et al., 2016). De forma ampla, o setor de serviços pode ser definido como o conjunto de atividades econômicas que produzem utilidades relativas a tempo, lugar, forma e benefícios psicológicos (Kon, 2004). As características básicas das empresas se serviços são: simultaneidade entre fornecimento e consumo do serviço, produção de bens intangíveis e perecíveis e atividade intensiva em trabalho. Tendo como base os diversos estudos acerca do setor, Calabria et al. (2013) apontam que as características do setor de serviços podem ser sintetizadas em quatro palavras: intangibilidade, heterogeneidade, inseparabilidade e perecibilidade (intangibility, heterogeneity, inseparability, and perishability, sigla IHIP). Metcalfe e Miles (1997), por sua vez, argumentam que por conta destas características, muitas empresas fornecedoras de serviços são de pequeno porte, entregam produtos intangíveis com restrições quanto à apresentação antecipada e dependem de interações frequentes entre cliente e fornecedor.

\subsection{Tipologias e Classificações dos Serviços}

Em relação à classificação dos serviços a literatura oferece uma gama de tipologias que são baseadas na produção, função e consumo dos serviços (Kon, 2004). Metcalfe e Miles (1997) dividem as empresas de serviços em três categorias principais: i) setores dominados por fornecedores, serviços públicos ou coletivos (p. ex. educação e cuidados de saúde), serviços pessoais (p. ex., alimentos e bebidas) e comércio varejista; ii) (a) setores intensivos em escala de produção que envolvem tarefas administrativas de backoffice em grande escala e (b) setores de rede: dependentes de redes físicas (p. ex., serviços de transporte e viagens e comércio e distribuição por atacado) e em redes de informação elaboradas (p. ex., bancos, seguros, serviços de radiodifusão e telecomunicações); iii) fornecedores de tecnologia especializada e setores baseados em ciência, software, serviços de negócios especializados, serviços de laboratório e design. 
Czarnitzki e Spielkamp (2003), por sua vez, sinalizam que na Alemanha a definição mais comum do setor de serviços se baseia nos ramos da atividade econômica. A diferenciação ocorre, portanto, de acordo com o setor em que as empresas se baseiam, ou seja, onde a produção é encontrada. Com base na Nomenclatura Estatística das Atividades Econômicas na Comunidade Europeia (NACE Rev. 1) os autores propõem uma divisão do setor de serviços em quatro eixos principais: Comércio, Serviços Financeiros/Seguros, Transportes e Serviços Relacionados à Produção.

A classificação proposta pelos autores utiliza termos como "serviços relacionados à produção", "intensivos em conhecimento", "intensivos em tecnologia", sem apresentar uma definição clara dos mesmos. Além disso, nota-se que os serviços são diferenciados com base nos clientes aos quais a produção é predominantemente dirigida em termos de valor agregado. O problema com este método é que o mesmo considera apenas as relações externas, mas não internas. Uma consequência disso é que os serviços gerados dentro de uma indústria não considerados na classificação setorial, tornando esta categorização inconsistente.

Neste prisma, Abdal et al. (2016) afirmam que é mais complexo conceituar o setor de serviços que o setor industrial, devido à alta heterogeneidade de sua configuração técnica, baixa disponibilidade de informações estatísticas e atenção limitada por parte dos analistas. Utilizando uma classificação do setor de serviços inspirada pela tipologia da Eurostat (2008), os autores agrupam os serviços em dois grupos: intensivos em conhecimento ou não intensivos em conhecimento. Dentre as principais características dos Serviços Intensivos em Conhecimento (Knowledge Intensive Services - KIS) estão: esforço significativo em P\&D, elevado esforço em inovação; uso intensivo de tecnologias da informação; e mão de obra qualificada. Abdal et al. (2016) dividem os Serviços Intensivos em Conhecimento em cinco grupos principais: KIS-Tecnológico; KIS-Profissional; KIS-Financeiro; KIS-Social e KIS-Mídia e Cultura. Neste artigo especificamente, iremos trabalhar com a categoria de Serviços Empresariais Intensivos em Conhecimento (Knowledge Intensive Business Services - KIBS), que englobam os serviços intensivos em conhecimento prestados às empresas. Na próxima seção discutiremos este conceito de maneira mais detalhada.

\subsection{Definição de Serviços Empresariais Intensivos em Conhecimento (KIBS)}

Como já foi citado anteriormente, nos últimos trinta anos as transformações ocorridas no capitalismo global criaram condições significativas para o crescimento dos serviços, sobretudo àqueles voltados às empresas (Torres-Freire, 2006). Como sinaliza Kubota (2006; 2009), os serviços que as empresas industriais exerciam internamente no passado, tornaram-se gradativamente serviços especializados ofertados fora do âmbito das empresas, a exemplo de serviços de informática e de consultoria. Neste contexto, Miozzo e Grimshaw (2006) enfatizam que os provedores externos de serviços se tornaram cada vez mais especializados e o mercado de serviços contratados cresceu exponencialmente. Uma parte destes serviços é classificada como Knowledge Intensive Business Services (KIBS), ou seja, Serviços Empresariais Intensivos em Conhecimento.

Segundo Miles (2005), KIBS podem ser definidos como "atividades econômicas que têm como resultado a criação, acumulação ou disseminação de conhecimento". No entanto, Muller e Doloreux (2016) apontam que não há um consenso sobre a definição precisa de KIBS. Schmitt et al. (2012), por seu turno, reúnem diversos conceitos de KIBS encontrados na literatura (ver, p. ex., Bettencourt et al., 2002; Grimshaw e Miozzo, 2005; Simie e Stranback, 2006; Amara et al., 2008; Muller e Doloreux, 2009; Wenhong e Min, 2010).

Mais recentemente, Muller e Doloreux (2016) somaram-se a este esforço fazendo um apanhado das principais definições de KIBS disponíveis. Os autores sinalizam que, de forma ampla, os KIBS são empresas especializadas que prestam serviços a outras empresas e organizações e que tem como resultado a geração, acumulação e difusão do conhecimento (Miles et al., 1995). Den Hertog (2000), por sua vez, propôs uma definição mais precisa de KIBS: empresas privadas ou organizações que dependem fortemente de conhecimentos profissionais, ou seja, conhecimentos relacionados com uma disciplina (técnica) específica ou domínio (técnico) funcional para fornecer produtos e serviços intermediários que 
são baseados no conhecimento. Já Bettencourt et al. (2002) consideram KIBS como empresas cujas principais atividades de valor agregado consistem na acumulação, criação ou disseminação de conhecimento, com a finalidade de desenvolver um serviço personalizado ou solução de produto para satisfazer as necessidades do cliente.

Finalmente, Torres-Freire (2006) apresenta uma definição multifacetada de KIBS, caracterizando-os pela: i) participação expressiva em valor adicionado; ii) utilização de recursos humanos de mais alta qualificação comparado a outros setores da economia; iii) atuação em fontes primárias de informação e de conhecimento, fornecimento de tecnologias de informação e auxílio a processos de inovação; e iv) capacidade de proporcionar alta interação produtor-usuário.

\subsection{Tipologias e Classificações dos KIBS}

Miles et al. (1995) classificam os Serviços Empresariais Intensivos em Conhecimento em duas categorias principais: a primeira se refere aos serviços tradicionais tais como consultoria gerencial, publicidade, serviços jurídicos, entre outros; ao passo que a segunda categoria está relacionada ao conhecimento técnico e a transferência deste conhecimento, incluindo serviços de arquitetura e engenharia, serviços de pesquisa médica e farmacêutica, P\&D, entre outros. Já o National Science Board (2008) sugere uma classificação alternativa de KIBS, também estruturada em duas categoriais básicas: i) serviços orientados pelo mercado, tais como comunicação, finanças, desenvolvimento de software e serviços como consultoria gerencial; e ii) serviços orientados pelo setor público, por exemplo, educação, saúde, entretenimento e turismo.

Apesar de não haver uma abordagem padrão para KIBS, Muller e Doloreux (2016) indicam que existe algum consenso sobre os ramos e empresas que compõem este segmento. A categorização mencionada pelos autores tem como base a NACE, e inclui atividades relacionadas à computação, pesquisa e desenvolvimento, atividades jurídicas e de consultoria técnica e gerencial.

$\mathrm{Na}$ literatura também é comum encontrar uma diferenciação entre os Professional-KIBS (serviços profissionais tradicionais tais como contabilidade e assessoria jurídica) e os Technical-KIBS (serviços relacionados à tecnologia, como serviços de informática e serviços de engenharia). Recentemente, houve a inclusão de uma terceira categoria: os Creative-KIBS (serviços de negócios criativos, como publicidade, design industrial, arquitetura e alguns outros serviços que envolvem elementos estéticos e capacidade criativa).

\subsection{KIBS e Inovação}

Antigamente, os KIBS eram vistos apenas como agentes que apoiavam os processos de inovação de seus clientes, e, de tempos em tempos, adotavam tecnologias desenvolvidas em outros lugares (Muller e Doloreux, 2016). Entretanto, o crescimento o setor de serviços e a mudança de seu papel na economia e na sociedade conjugado ao aumento da importância da inovação tecnológica no desenvolvimento econômico contribuíram para tornar os KIBS em protagonistas dos processos de inovação, que são cada vez mais dependentes do aprendizado interativo em rede.

Neste contexto, os KIBS atualmente estão sendo reconhecidos não apenas como fornecedores de conhecimento, mas como coprodutores de conhecimento e inovação em colaboração com seus clientes. Deste modo, os Serviços Empresariais Intensivos em Conhecimento formam uma categoria à parte em relação aos outros serviços, caracterizada por um alto potencial inovador (Muller e Doloreux, 2016) e como capazes de facilitar a inovação em outros setores econômicos, incluindo os setores industriais e manufatureiros (Guimarães, 2011), tendo papel relevante no desenvolvimento econômico de longo prazo.

\section{METODOLOGIA}

Em primeiro lugar foi realizada uma pesquisa bibliográfica utilizando o Portal de Periódicos da CAPES (http://www.periodicos.capes.gov.br/), a partir da busca e cruzamento das seguintes palavras-chave: Serviços Empresariais Intensivos em Conhecimento (KIBS), inovação, empreendedorismo e desenvolvimento econômico. As pesquisas foram feitas com as palavras em português e seus equivalentes 
em inglês. Foram considerados somente os artigos publicados nos cinco anos anteriores ${ }^{1}$ em periódicos avaliados por pares e com fator de impacto maior do que 1. Após o término do levantamento foram selecionados 22 artigos para a realização da revisão bibliográfica, tendo como critério a adequação dos mesmos ao contexto da pesquisa. Na etapa seguinte foi feita uma revisão bibliográfica com base nos artigos selecionados acerca das características dos KIBS e da sua relação com a inovação e o desenvolvimento econômico. Esta revisão também serviu de base para a delimitação do conceito de KIBS utilizado na pesquisa.

Posteriormente, a escolha dos segmentos de KIBS que serviram de base para a pesquisa foi feita em duas etapas. Como as classificações encontradas na literatura seguem predominantemente a NACE, recorremos às categorias propostos na Nota Técnica acerca da Classificação das Atividades de Serviços (Machado et al., 2015) para delimitar os segmentos a serem analisados. A Nota se baseia nos trabalhos de Eichengreen e Gupta (2009) e Arbache (2014) para determinar uma tipologia de serviços a partir das atividades presentes na Classificação Nacional da Atividade Econômica (CNAE/IBGE). Deste modo, selecionamos apenas as divisões da CNAE 2.0 que incluíam os seguintes serviços: serviços para empresas, serviços modernos, agregação de valor, e Professional Business Services (PBS).

Do total de segmentos encontrados que atendiam a todos os critérios detalhados anteriormente, consideramos ainda o perfil e as características da economia fluminense para chegar a lista final dos segmentos a serem analisados nesta pesquisa. Para tornar a análise mais rigorosa, optamos por utilizar como parâmetro as Classes da CNAE 2.0² (4 dígitos), e não as divisões, pois estas últimas incluíam atividades que não poderiam ser consideradas KIBS. Foram assim selecionados inicialmente 17 segmentos ${ }^{3}$.

Após a escolha dos segmentos, o próximo passo foi a definição da demanda por capacitação destes segmentos nos municípios e regiões do estado, realizada com base na identificação da concentração de atividades econômicas relacionadas a estes segmentos. Optamos por trabalhar com a concentração de atividades ao invés de considerar apenas a quantidade de empregos, na medida em que a mesma pode ser considerada como uma proxy da vocação econômica da região (La Rovere e Paranhos, 2011). Para mensurar a concentração de atividades seguimos o método proposto por Britto (2004) e utilizado por La Rovere e Paranhos (2011) tendo como base indicadores econômicos construídos a partir de dados coletados na Relação Anual de Indicadores Sociais do Ministério do Trabalho e Emprego (RAIS/MTE). Os indicadores utilizados foram o Quociente Locacional (QL), o Índice de Relevância Setorial (RS) e o Índice de Importância Municipal (IM), considerando tanto os dados relativos à emprego quanto à remuneração. O Quadro 1 detalha a fórmula de cálculo de cada um dos indicadores.

\section{Quadro 1: Indicadores de Concentração Econômica}

\begin{tabular}{|l|}
\hline Quociente Locacional \\
\hline $\begin{array}{l}\text { QLe }=(\text { Emprego do setor i no município/ Total de emprego do município) / (Total de emprego do setor i no País/ Total do } \\
\text { emprego no País })>1\end{array}$ \\
$\begin{array}{l}\text { QLr }=\text { (Remunerações do setor i no município/ Total de remunerações do município) / (Total de remunerações do setor i no } \\
\text { País/ Total do remunerações no País })>1\end{array}$ \\
\hline
\end{tabular}

\footnotetext{
${ }^{1}$ Considerando a época que a pesquisa foi feita os artigos selecionados foram publicados entre 2011 e 2016.

${ }^{2}$ A CNAE 2.0 se divide em Seções, Divisões, Grupos, Classes e Subclasses, em uma sequencia que vai do mais geral (Seções) ao mais específico (Subclasses). As classificações das atividades podem ser consultadas em: https://cnae.ibge.gov.br/?view=atividades

3 Os segmentos selecionados foram: Desenvolvimento de Programas de Computador sob Encomenda; Desenvolvimento e Licenciamento de Programas de Computador Customizáveis; Desenvolvimento e Licenciamento de Programas de Computador Não-Customizáveis; Consultoria em Tecnologia da Informação; Suporte Técnico, Manutenção e Outros Serviços em Tecnologia da Informação; Tratamento de Dados, provedores de Serviços de Aplicação e Serviços de Hospedagem na Internet; Portais, Provedores de Conteúdo e Outros Serviços de Informação na Internet; Atividades de Consultoria em Gestão Empresarial; Serviços de Arquitetura; Serviços de Engenharia; Atividades Técnicas Relacionadas à Arquitetura e Engenharia; Pesquisa e Desenvolvimento Experimental em Ciências Físicas e Naturais; Agências de Publicidade; Atividades de Publicidade não especificadas anteriormente; Pesquisas de Mercado e de Opinião Pública; Design e Decoração de Interiores; Atividades Profissionais, Científicas e Técnicas não especificadas anteriormente.
} 


\begin{tabular}{|l|}
\hline Índice de Relevância Setorial \\
\hline $\mathrm{RSe}=$ (Emprego do setor i no município) / (Total de emprego do setor i no País) $>0,1 \%$ \\
\hline $\mathrm{RSr}=$ (Remunerações do setor i no município) / (Total de remunerações do setor i no País) $>0,1 \%$ \\
\hline Índice de Importância Municipal \\
\hline $\mathrm{IMe}=$ (Emprego do setor i no município / Total de emprego do município) $>0,1 \%$ \\
\hline $\mathrm{IMr}=$ (Remunerações do setor i no município / Total de remunerações do município) $>0,1 \%$ \\
\hline
\end{tabular}

Fonte: Britto (2004); La Rovere e Paranhos (2011)

Feitos os cálculos dos seis indicadores para todos os municípios do estado, os resultados foram interpretados a partir de alguns parâmetros. O primeiro é a seleção dos municípios nos quais os segmentos apresentam QLe e QLr maior do que um. O segundo se refere à seleção dos segmentos com RSe e RSr maiores que $0,1 \%$, indicando uma participação mínima do município no emprego e na remuneração naquele segmento no total do país. O terceiro parâmetro diz respeito ao IMe e IMr, que também precisam ser superiores a $0,1 \%$, indicando um percentual mínimo de participação do segmento no emprego e na remuneração no âmbito do município. O quarto introduz um filtro ao estabelecer um mínimo de três estabelecimentos para se considerar que o município realmente possui uma concentração econômica no segmento em questão.

Depois de aplicarmos todos os filtros aos cálculos realizados pudemos observar quais os segmentos que apresentaram relevância em pelo menos um município do ERJ. Neste caso, 11 dos 17 segmentos selecionados apresentaram relevância na economia fluminense. Antes de começar a levantar a oferta por capacitação decidimos agregar estes segmentos em cinco grandes categorias para facilitar a análise dos resultados e a definição dos cursos relacionados aos mesmos. O Quadro 2 apresenta as categorias e seus respectivos segmentos.

Quadro 2: Categorias e Respectivos Segmentos

\begin{tabular}{|c|c|c|}
\hline \multicolumn{2}{|c|}{ Categorias } & Segmentos \\
\hline \multirow{5}{*}{ Tecnologia da Informação } & \multirow{2}{*}{$\begin{array}{l}\text { Desenvolvimento de } \\
\text { Programas de Computador } \\
\text { e Consultoria }\end{array}$} & $\begin{array}{l}\text { Desenvolvimento de Programas de Computador sob } \\
\text { Encomenda }\end{array}$ \\
\hline & & Consultoria em Tecnologia da Informação \\
\hline & \multirow{3}{*}{$\begin{array}{l}\text { Suporte Técnico, } \\
\text { Tratamento de Dados e } \\
\text { Portais }\end{array}$} & $\begin{array}{l}\text { Suporte Técnico, Manutenção e Outros Serviços em } \\
\text { Tecnologia da Informação }\end{array}$ \\
\hline & & $\begin{array}{l}\text { Tratamento de Dados, provedores de Serviços de Aplicação e } \\
\text { Serviços de Hospedagem na Internet }\end{array}$ \\
\hline & & $\begin{array}{l}\text { Portais, Provedores de Conteúdo e Outros Serviços de } \\
\text { Informação na Internet }\end{array}$ \\
\hline \multicolumn{2}{|l|}{ Gestão } & Atividades de Consultoria em Gestão Empresarial \\
\hline \multirow{3}{*}{\multicolumn{2}{|c|}{ Engenharia e Arquitetura }} & Serviços de Arquitetura \\
\hline & & Serviços de Engenharia \\
\hline & & Atividades Técnicas Relacionadas à Arquitetura e Engenharia \\
\hline \multicolumn{2}{|l|}{ Pesquisa e Desenvolvimento } & $\begin{array}{l}\text { Pesquisa e Desenvolvimento Experimental em Ciências Físicas } \\
\text { e Naturais }\end{array}$ \\
\hline \multicolumn{2}{|c|}{ Outras Atividades Profissionais, Científicas e Técnicas } & $\begin{array}{l}\text { Atividades Profissionais, Científicas e Técnicas não } \\
\text { especificadas anteriormente }\end{array}$ \\
\hline
\end{tabular}

Fonte: Elaboração Própria

Como a categoria "Outras Atividades Profissionais, Científicas e Técnicas não especificadas anteriormente" apresenta grande heterogeneidade e formação predominantemente de nível técnico, será preciso retrabalhar esta categoria, eliminando serviços pouco intensivos em conhecimento, e fazer a comparação entre oferta e demanda destes serviços apenas quando tivermos os dados sobre cursos técnicos. Optamos assim por excluí-la da nossa análise no momento.

Após a identificação dos municípios que apresentam concentrações de atividades econômicas nos segmentos selecionados, utilizamos um último filtro ligado à escolaridade da mão de obra, excluindo os 
municípios onde o número de empregados com nível superior completo e incompleto em relação ao total de empregados no segmento é menor do que o número de empregados com nível superior completo e incompleto em relação ao total de empregados no segmento no ERJ. Optamos por utilizar este filtro uma vez que a literatura sugere que os KIBS se caracterizam por ter empregos de alta qualificação.

Com as categorias definidas passamos à etapa de levantamento da oferta de capacitação para cada uma delas. Em primeiro lugar definimos os cursos, de nível superior e de pós-graduação ${ }^{4}$ relacionados a cada categoria. Consideramos tanto cursos diretamente relacionados a categorias e seus segmentos quanto cursos que podem apoiá-los de maneira indireta. Esta seleção teve como base a especificação das atividades relativas aos segmentos detalhadas na CNAE/IBGE. O Quadro 3 traz a lista de cursos relacionados às cinco categorias selecionadas para análise.

Quadro 3: Cursos Selecionados por Categoria

\begin{tabular}{|l|l|}
\hline \multicolumn{1}{|c|}{ Categorias } & \multicolumn{1}{c|}{ Cursos } \\
\hline \multirow{2}{*}{ Tecnologia da Informação } & $\begin{array}{l}\text { Ciência da Computação; Engenharia da Computação; Tecnologia e Desenvolvimento de } \\
\text { Software; Tecnologia da Informação; Sistema de Informação; Administração de Redes; } \\
\text { Tecnologia em Gestão de Telecomunicações; Jornalismo; Comunicação Social } \\
\text { (Redação e Conteúdo); e Publicidade e Propaganda. }\end{array}$ \\
\hline \multirow{2}{*}{ Gestão } & $\begin{array}{l}\text { Administração; Economia; Ciências Contábeis; Gestão de Pessoal /Recursos Humanos; } \\
\text { Hotelaria; Economia Doméstica. }\end{array}$ \\
\hline \multirow{3}{*}{ Engenharia e Arquitetura } & $\begin{array}{l}\text { Engenharia de Produção. Engenharia Mecânica. Engenharia Elétrica. Engenharia } \\
\text { Química. Engenharia Eletrônica. Engenharia Ambiental e Sanitária. Engenharia de } \\
\text { Telecomunicações. Engenharia de Controle e Automação. Engenharia Naval. } \\
\text { Engenharia de Materiais. Engenharia Metalúrgica. Engenharia Nuclear. Engenharia } \\
\text { Ambiental. Engenharia Elétrica. Engenharia Civil. Arquitetura e Urbanismo. }\end{array}$ \\
\hline Bioquímica Industrial. Engenharia Bioquímica. Farmácia. Química. Ciências \\
Biológicas. Engenharia Bioquímica. Tecnologia Química. Ciências Físicas. Medicina \\
Veterinária.
\end{tabular}

Fonte: Elaboração Própria

Para a definição da oferta de cursos de nível superior - única dimensão finalizada até o momento seguimos algumas etapas. Primeiramente, nos baseamos no Mapa da Ciência do Estado do Rio de Janeiro (FAPERJ, 2014) e em um estudo anterior feito por La Rovere et al. (2015) para identificar as instituições públicas e privadas de ensino superior presentes no estado. Cabe ressaltar que selecionamos não apenas as instituições localizadas nos municípios que apresentaram segmentos relevantes, mas também as instituições localizadas em municípios que estão nas áreas de influência das regiões que compõem o estado. Em seguida, consultamos o site do INEP (http://portal.inep.gov.br/indice-geral-de-cursos-igc-) para verificar o Índice Geral de Cursos (IGC) de cada instituição, definindo um mínimo de 3 para que a instituição fosse incluída no levantamento.

Por fim, utilizamos a plataforma DataViva (http://www.dataviva.info/pt/) que reúne diferentes bases de dados oficiais, dentre elas a do INEP, para consultar o total de concluintes em cada um dos cursos e instituições selecionadas. O dado mais recente disponível na plataforma refere-se ao ano de 2014. Optamos utilizar os dados relativos aos concluintes, e não apenas o total de cursos ou vagas oferecidas, para controlar os efeitos de evasão e distorção de tempo para se formar que são bastante comuns no Ensino Superior. Após os dados coletados de cada instituição e de cada curso procedemos com a agregação dos mesmos e construímos os gráficos de oferta de capacitação referente a cada categoria.

$\mathrm{Na}$ última etapa da pesquisa foi feito o cruzamento entre a oferta e a demanda de capacitação para cada categoria, considerando as principais regiões do estado: Rio de Janeiro, Metropolitana, Norte e Noroeste Fluminense, Baixadas Litorâneas, Serrana, Centro-Sul Fluminense, Médio Paraíba e Costa Verde. Este cruzamento teve como objetivo identificar a correspondência entre oferta e a demanda por capacitação referente aos Serviços Empresariais Intensivos em Conhecimento relevantes para o estado, possibilitando

\footnotetext{
${ }^{4}$ Até o momento só fizemos o levantamento dos cursos de nível superior. Posteriormente iremos incluir na nossa análise os dados dos cursos de pós-graduação stricto e lato sensu.
} 
a reflexão de que forma as condições de capacitação afetam as possibilidade de desenvolvimento de inovações.

O ordenamento da oferta de capacitação foi feita com base no número absoluto de concluintes do total de cursos relacionados às cinco categorias em questão. Do lado da demanda, o ordenamento seguiu três critérios. Em primeiro lugar, consideramos os municípios que apresentam os maiores índices de QLe. Em seguida, levamos em conta a presença de municípios de cada região em mais de um segmento - no caso das categorias que eram compostas por mais de um segmento. Por fim, com intuito de tornar a análise mais rigorosa, nos casos em que os índices de QLe eram próximos, recorremos ao indicador de Relevância Setorial (RSe) para definir a ordem das regiões. Neste caso, calculamos a razão entre os índices de RSe e de QLe dos municípios em questão, considerando como numerador sempre o maior valor. Deste modo, se a razão entre o RSe dos municípios fosse maior do que a razão entre o QLe dos mesmos, a região em que se localiza o município com maior Relevância Setorial era ordenada em uma posição superior. Se o resultado fosse o contrário, a região que abrange o município com maior QLe ficava a frente. A seguir vamos apresentar e discutir os resultados encontrados.

\section{RESULTADOS}

\subsection{Demanda de Capacitação por Segmento}

A identificação da demanda por capacitação foi feita a partir do procedimento apresentado na Metodologia: i) cálculo dos indicadores QLe, QLr, RSe, RSr, IMe, IMr; ii) identificação dos municípios que alcançaram os valores mínimos necessários em todos os indicadores simultaneamente; iii) aplicação do filtro de 3 estabelecimentos por município iv) exclusão dos municípios onde a proporção de empregos de nível superior completo e incompleto no segmento selecionado é menor do que a média estadual. Nesta seção vamos apresentar os resultados encontrados elencando os municípios com maior concentração de atividades econômicas em cada macrorregião nos segmentos selecionados que atenderam a todos os requisitos. Por questões de espaço, optamos por explicitar apenas os dados relativos ao QLe e ao RSe, pois os mesmos serviram de base para o ordenamento das macrorregiões em cada segmento que foi utilizado posteriormente para fazer o cruzamento entre oferta e demanda.

\subsubsection{TI: Desenvolvimento de Programas e Consultoria}

Em relação à categoria "TI - Desenvolvimento de Programas de Computador e Consultoria", que inclui os segmentos "Desenvolvimento de Programas de Computador sob Encomenda" e "Consultoria em Tecnologia da Informação", observa-se que o Rio de Janeiro possui a maior demanda por capacitação. Mesmo com um QLe menor do que o de outros municípios (1,79 e 1,89 respectivamente), a capital do estado possui uma Relevância Setorial em ambos os segmentos que compõem a categoria significativamente superior a de todos os outros municípios que apresentaram resultado $(9,39 \%$ e $9,94 \%$ respectivamente). Em segundo lugar, destaca-se a região Norte Fluminense se destaca com o maior QLe de Consultoria em Tecnologia da Informação e o terceiro maior índice de relevância setorial desta categoria. Por fim, observam-se concentrações no município de Niterói (Região Metropolitana).

Tabela 1: Demanda por Capacitação na Categoria TI - Desenvolvimento de Programas de Computador e Consultoria

\begin{tabular}{|c|c|c|c|}
\hline \multirow{2}{*}{ Categoria } & \multicolumn{2}{c|}{ TI: Desenvolvimento de Programas de Computador e Consultoria } \\
\cline { 2 - 4 } Atividades & \multirow{2}{*}{ Indicadores } \\
\cline { 2 - 4 } & Municípios & 1,790419 & $9,39 \%$ \\
\hline \multirow{2}{*}{$\begin{array}{c}\text { Desenvolvimento de Programas de } \\
\text { Computador sob Encomenda }\end{array}$} & Rio de Janeiro & 1,141353 & $0,45 \%$ \\
\cline { 2 - 4 } & Niterói & 1,895271814 & $9,94 \%$ \\
\hline \multirow{2}{*}{$\begin{array}{c}\text { Consultoria em Tecnologia da } \\
\text { Informação }\end{array}$} & Rio de Janeiro & 4,814495071 & $0,99 \%$ \\
\cline { 2 - 4 } & Campos dos Goytacazes & 2,039749253 & $0,81 \%$ \\
\hline
\end{tabular}

Fonte: Elaboração Própria 


\subsubsection{TI: Suporte Técnico, Tratamento de Dados e Portais}

A categoria "TI - Suporte Técnico, Tratamento de Dados e Portais" que abrange os segmentos "Suporte Técnico, Manutenção e Outros Serviços em Tecnologia da Informação", "Tratamento de Dados, Provedores de Serviços de Aplicação e Serviços de Hospedagem na Internet" e "Portais, Provedores de Conteúdo e Outros Serviços de Informação na Internet", a capital do estado figura novamente como líder, destacando-se nas atividades de Suporte Técnico (QLe=1,52; RSe=8,01\%) e Tratamento de Dados (QLe=1,41; RSe=7,43\%). O município de Nova Friburgo apresentou QLe e RSe relevantes no segmento "Portais, Provedores de Conteúdo e Outros Serviços de Informação" mas foi excluído pelo filtro de escolaridade.

Tabela 2: Demanda por Capacitação na Categoria TI - Suporte Técnico, Tratamento de Dados e Portais

\begin{tabular}{|c|c|c|c|}
\hline \multirow{2}{*}{ Categoria } & \multicolumn{2}{|c|}{ TI: Suporte Técnico, Tratamento de Dados e Portais } \\
\cline { 2 - 4 } Atividades & Municípios & \multicolumn{2}{|c|}{ QLe } \\
\cline { 2 - 4 } & RSe (\%) \\
\hline $\begin{array}{c}\text { Suporte Técnico, Manutenção e Outros Serviços em } \\
\text { Tecnologia da Informação }\end{array}$ & Rio des Janeiro & $8,01 \%$ \\
\hline $\begin{array}{c}\text { Tratamento de Dados, Provedores de Serviços de } \\
\text { Aplicação e Serviços de Hospedagem na Internet }\end{array}$ & Rio de Janeiro & 1,417496 & $7,43 \%$ \\
\hline
\end{tabular}

Fonte: Elaboração Própria

\subsubsection{Gestão}

Na categoria "Gestão", que abarca o segmento "Atividades de Consultoria e Gestão Empresarial”, apenas o município do Rio de Janeiro atendeu a todos os critérios estabelecidos, tendo um QLe de 3,08 e um RSe igual a $16,17 \%$ (ver Tabela 3 ).

Tabela 3: Demanda por Capacitação na Categoria Gestão

\begin{tabular}{|c|c|c|c|}
\hline \multirow{2}{*}{ Categoria } & \multicolumn{2}{|c|}{ Gestão } \\
\cline { 3 - 4 } Atividade & \multirow{2}{*}{ Municípios } & \multicolumn{2}{|c|}{ Indicadores } \\
\cline { 3 - 4 } Atividades de Consultoria e Gestão Empresarial & \multirow{2}{*}{ Rio de Janeiro } & 3,083428 & $1 \%, 17 \%$ \\
\hline
\end{tabular}

Fonte: Elaboração Própria

\subsubsection{Arquitetura e Engenharia}

A categoria Arquitetura e Engenharia, que engloba os segmentos "Serviços de Arquitetura", "Serviços de Engenharia" e "Atividades Técnicas Relacionadas à Arquitetura e Engenharia", foi a que apresentou inicialmente o maior número de municípios com concentrações econômicas. Porém, muitos municípios foram excluídos após a aplicação do filtro de escolaridade. Apenas um município (Niterói) apresentou concentração no segmento "Serviços de Arquitetura", porém a proporção de empregados com nível superior neste segmento é menor do que a média estadual, o que acabou levando à exclusão deste segmento da nossa análise.

A maior demanda por capacitação está na capital, que apesar de apresentar QLes menores que a Região Metropolitana, possui índices de relevância setorial expressivos, conforme exposto na tabela 4. A Região Metropolitana, representada pelos municípios de Rio Bonito e Itaboraí, destaca-se em segundo lugar. Em terceiro lugar, vem a Região Centro-Sul Fluminense, representada por Resende.

Tabela 4: Demanda por Capacitação na Categoria Arquitetura e Engenharia

\begin{tabular}{|c|c|c|c|}
\hline \multirow{2}{*}{ Categoria } & \multicolumn{3}{|c|}{ Arquitetura e Engenharia } \\
\cline { 2 - 4 } Atividades & \multirow{2}{*}{ Municípios } & \multicolumn{2}{|c|}{ QLe } \\
\cline { 2 - 4 } & & 2,182153848 & $237,99 \%$ \\
\hline \multirow{2}{*}{ Serviços de Engenharia } & Rio de Janeiro & 3,747153978 & $3,15 \%$ \\
\cline { 2 - 4 }
\end{tabular}




\begin{tabular}{|c|c|c|c|}
\hline \multirow{2}{*}{$\begin{array}{c}\text { Atividades Técnicas Relacionadas à Engenharia e } \\
\text { Arquitetura }\end{array}$} & Rio de Janeiro & 1,684849837 & $8,84 \%$ \\
\cline { 2 - 4 } & Itaboraí & 4,518698155 & $0,30 \%$ \\
\cline { 2 - 4 } & Resende & 2,38555753 & $0,18 \%$ \\
\hline
\end{tabular}

Fonte: Elaboração Própria

\subsubsection{Pesquisa e Desenvolvimento}

No que diz respeito à categoria "Pesquisa e Desenvolvimento", que compreende o segmento "Pesquisa e Desenvolvimento Experimental em Ciências Físicas e Naturais", só se revelou uma concentração econômica no município do Rio de Janeiro, que possui QLe igual a 2,99 e um RSe de 21,43\% como evidencia a Tabela 5.

Tabela 5: Demanda por Capacitação na Categoria Pesquisa e Desenvolvimento

\begin{tabular}{|c|c|c|c|}
\hline \multirow[b]{3}{*}{ Atividade } & \multicolumn{3}{|c|}{ Pesquisa e Desenvolvimento } \\
\hline & \multirow{2}{*}{ Municípios } & \multicolumn{2}{|c|}{ Indicadores } \\
\hline & & QLe & $\operatorname{RSe}(\%)$ \\
\hline $\begin{array}{c}\text { Pesquisa e Desenvolvimento } \\
\text { Experimental em Ciências Físicas e } \\
\text { Naturais }\end{array}$ & Rio de Janeiro & 2,991652 & $21,43 \%$ \\
\hline
\end{tabular}

Fonte: Elaboração Própria

\subsection{Oferta de Capacitação por Segmento}

Como descrito na metodologia, o levantamento sobre a oferta de capacitação em nível superior foi feita a partir das seguintes etapas: i) definição dos cursos direta e indiretamente relacionados às categorias; ii) identificação das instituições de ensino superior públicas e privadas presentes no estado; iii) seleção das instituições com IGC maior que 3; iv) levantamento na plataforma DataViva dos concluintes em cada curso e em cada instituição no ano de 2014 (último dado disponível); v) agregação dos dados e construção dos gráficos. Nesta seção, vamos apresentar os resultados referentes a cada categoria. Cabe ressaltar que optamos por incluir nos gráficos tanto o total de concluintes quanto o total de cursos, pois algumas vezes um número menor ou igual de cursos resulta em um número maior de concluintes. Isto pode ocorrer por duas razões: a média do número de vagas oferecidas nos cursos em uma região pode ser maior do que em outra ou a evasão em uma região pode ser menor do que em outra.

\subsubsection{Tecnologia da Informaçãa ${ }^{5}$}

Em relação à categoria "Tecnologia da Informação", podemos observar no Gráfico 1 uma forte concentração da oferta de capacitação no município do Rio de Janeiro, que possui 52 cursos e graduou 2.703 estudantes em 2014. A Região Metropolitana está em segundo lugar com 27 cursos e 832 alunos graduados. A Região Serrana, que abriga um Parque Tecnológico voltado para este setor, ocupa a terceira colocação com 15 cursos e 149 concluintes. Nas últimas posições estão respectivamente Costa Verde, Médio Paraíba e Centro-Sul Fluminense ( 2 cursos e 112 graduados); Baixadas Litorâneas (5 cursos e 80 concluintes) e Norte e Noroeste Fluminense ( 9 cursos e 25 concluintes).

\subsubsection{Gestão}

No que diz respeito à categoria "Gestão" (ver Gráfico 2) verifica-se novamente uma expressiva concentração da oferta de capacitação na capital do estado que hospeda 66 cursos e graduou 6.727 estudantes em 2014. O entorno metropolitano aparece na segunda posição tendo 35 cursos e 3.284 concluintes. Em terceiro lugar está a Costa Verde, Médio Paraíba e Centro-Sul Fluminense, que mesmo tendo apenas 12 cursos registrou 534 formandos em 2014. As (macro)regiões Serrana (16 cursos e 392

\footnotetext{
${ }^{5}$ Em relação à oferta de capacitação optamos por não dividir a categoria Tecnologia da Informação entre Desenvolvimento de Programas e Consultoria e Suporte, Tratamento de Dados e Portais como foi feito em relação à demanda e ao cruzamento entre oferta e demanda. Deste modo, consideramos Tecnologia da Informação como uma única categoria que servirá para ambas as subcategorias na hora de fazer o cruzamento. Os cursos relativos à categoria estão detalhados na seção de Metodologia.
} 
concluintes); Norte e Noroeste Fluminense (16 cursos e 375 graduados); e Baixadas Litorâneas (5 cursos e 205 concluintes) ocupam a quarta, quinta e sexta posições respectivamente.

\subsubsection{Arquitetura e Engenharia}

Quanto à categoria "Arquitetura e Engenharia” (ver Gráfico 3) novamente nota-se um amplo domínio do município do Rio de Janeiro em relação à oferta de capacitação. A cidade possui 77 cursos e graduou 4.048 estudantes em 2014. Com 25 cursos e 1.347 concluintes a Região Metropolitana é o segundo centro de formação do estado. Em terceiro e quarto lugares aparecem respectivamente Costa Verde, Médio Paraíba e Centro-Sul Fluminense ( 24 cursos e 605 graduados) e Norte e Noroeste Fluminense (9 cursos e 553 concluintes). Nas últimas posições estão a Região Serrana, com apenas 4 cursos e 159 formandos, e a Região das Baixadas Litorâneas, com somente 5 cursos e 121 concluintes.

\section{$\underline{4.2 .4}$ Pesquisa e Desenvolvimento}

Ao contrário das outras categorias, a categoria "Pesquisa e Desenvolvimento" (Gráfico 4) tem como principal ofertante de capacitação a Região Metropolitana, com 30 cursos e 1.240 concluintes, seguida pela cidade do Rio de Janeiro que possui 23 cursos e formou 1.135 estudantes em 2014. Com desempenho semelhante as (Macro)regiões Serrana e Norte e Noroeste Fluminense ocupam a $3^{\mathrm{a}}$ e a $4^{\mathrm{a}}$ posições respectivamente. Enquanto a primeira possui 9 cursos e 215 graduados, a segunda possui 11 cursos e 207 concluintes. Nas últimas posições encontram-se Costa Verde, Médio Paraíba e Centro-Sul Fluminense ( 4 cursos e 62 concluintes) e Baixas Litorâneas ( 1 curso e 40 formandos).

\section{Gráfico 1: Oferta de Capacitação na Categoria Tecnologia da Informação}

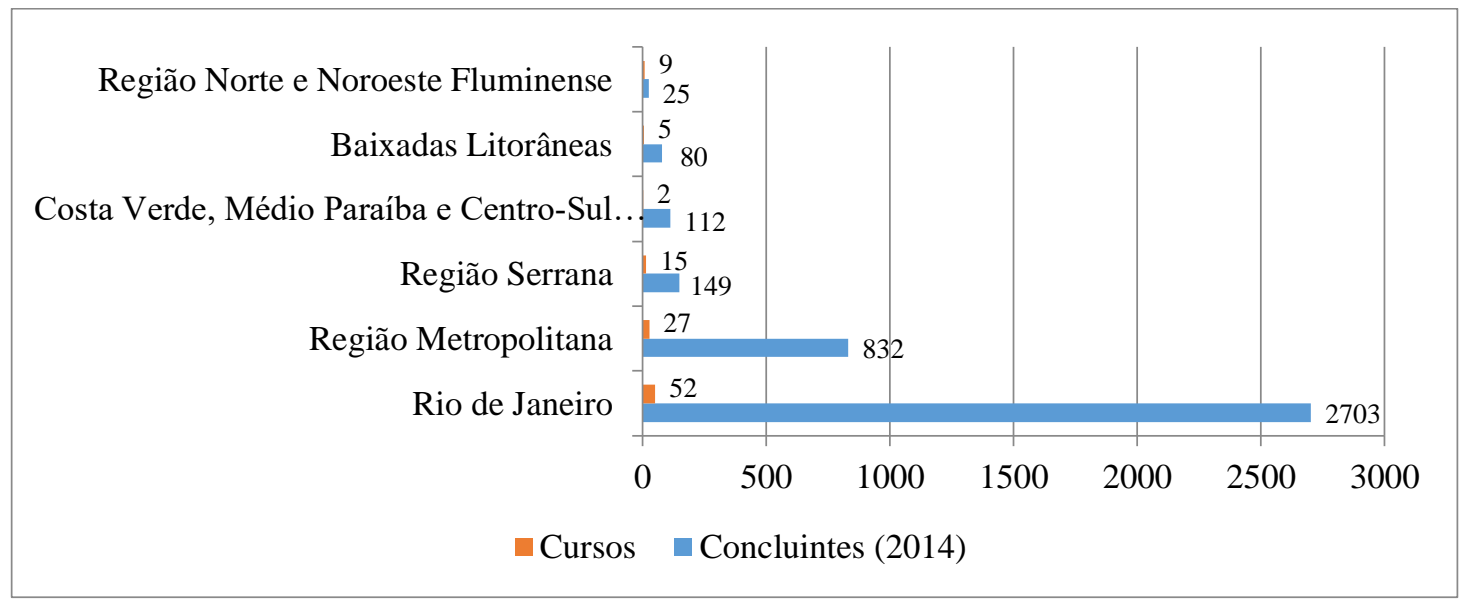

Fonte: Elaboração Própria

Gráfico 2: Oferta de Capacitação na Categoria Gestão

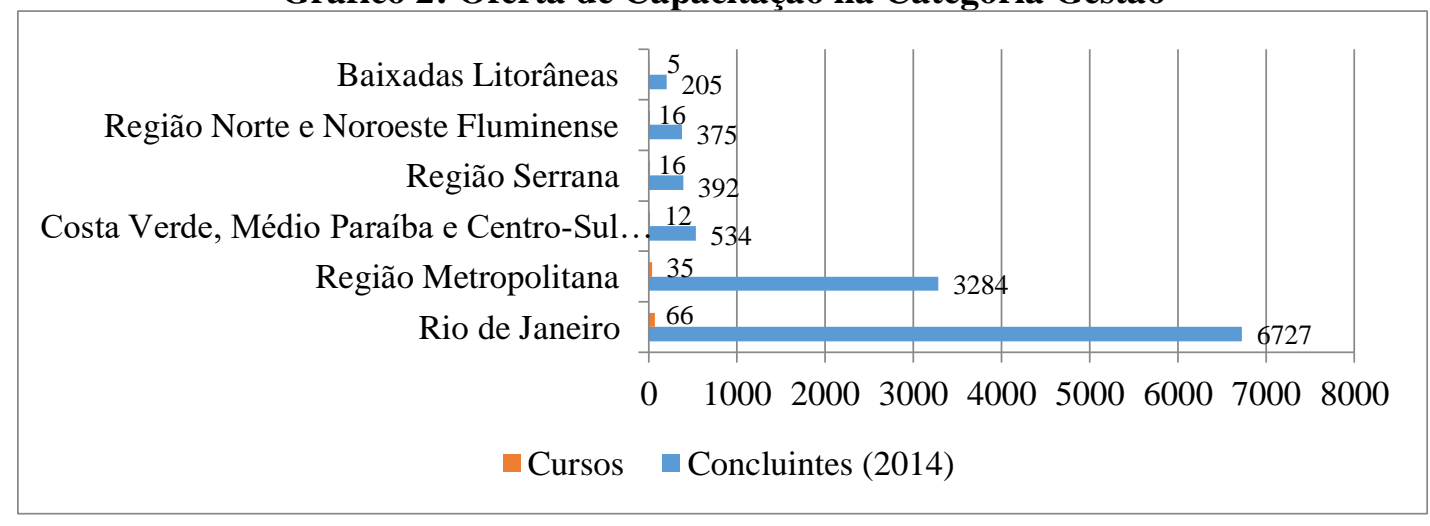

Fonte: Elaboração Própria 


\subsection{Cruzamento entre Demanda e Oferta}

A última etapa da pesquisa foi o cruzamento entre a demanda por e oferta de capacitação em quatro das cinco categorias analisadas, a fim de identificar possíveis ambientes de inovação no estado. Os critérios para o ordenamento de demanda e oferta já foram detalhados na seção de metodologia. Nesta seção vamos apresentar os resultados encontrados verificando a correspondência ou não correspondência entre oferta e demanda em cada uma das categorias.

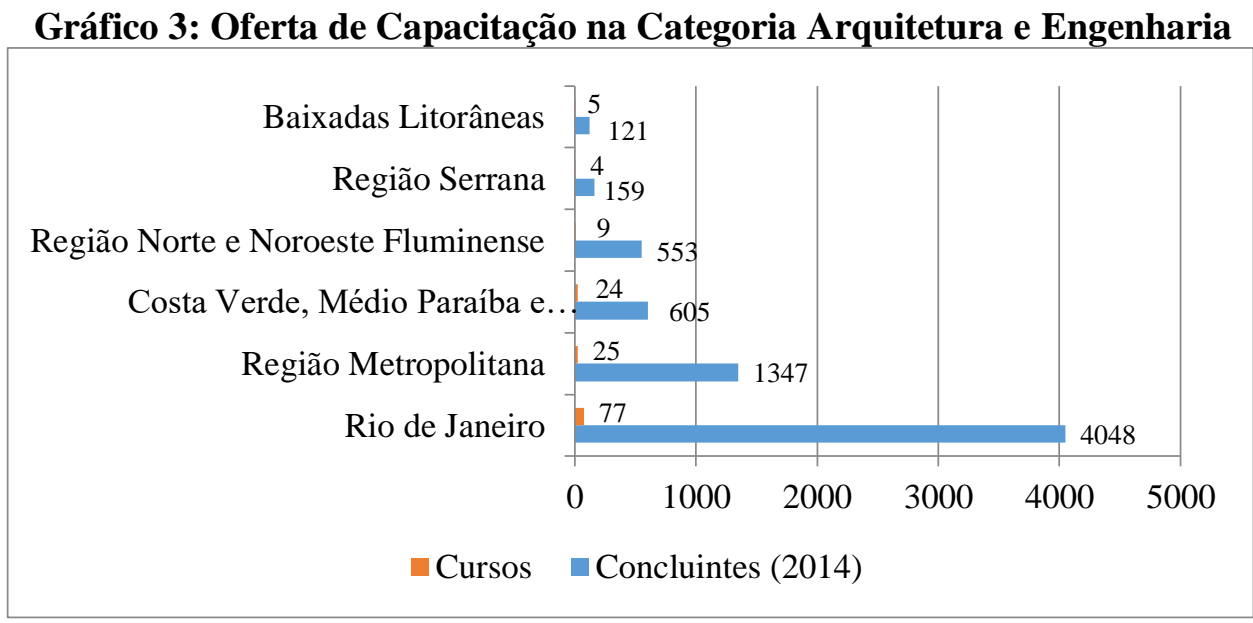

Fonte: Elaboração Própria

Gráfico 4: Oferta de Capacitação na Categoria Pesquisa e Desenvolvimento

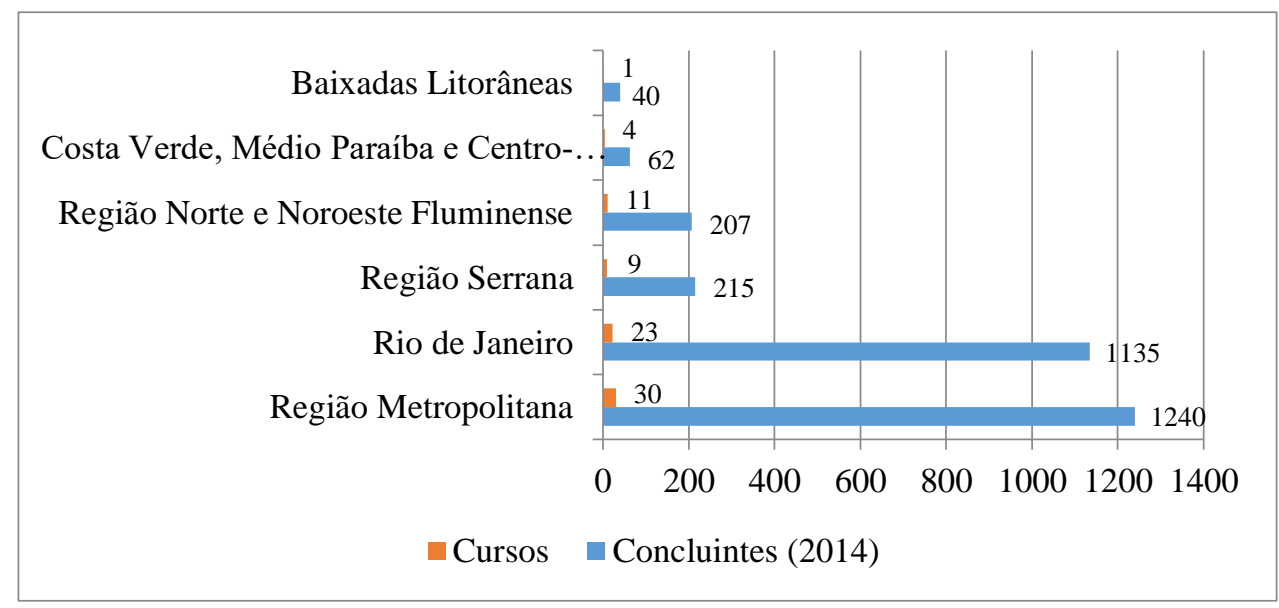

Fonte: Elaboração Própria

\subsubsection{TI: Desenvolvimento de Programas e Consultoria}

Em relação à categoria “TI - Desenvolvimento de Programas de Computador e Consultoria", verificou-se uma correspondência no município do Rio de Janeiro, que é ao mesmo tempo o principal demandante e o principal ofertante de capacitação nos segmentos que compõem a categoria. Há também uma correspondência na Região das Baixadas Litorâneas, mas a mesma só ocupa a quarta posição. O que chama mais atenção no cruzamento desta categoria é a Macrorregião Norte e Noroeste Fluminense, que apesar de ter a segunda maior demanda por capacitação, encontra-se na última colocação em relação à oferta de capacitação. O Quadro 8 traz o cruzamento completo.

Quadro 4: Cruzamento entre Oferta e Demanda na Categoria "TI - Desenvolvimento de Programas de Computador e Consultoria"

\begin{tabular}{|c|c|c|c|}
\hline \multicolumn{4}{|c|}{ TI: Desenvolvimento de Programas de Computador e Consultoria } \\
\hline Ordem & Demanda & Oferta & Cruzamento \\
\hline 1 & Rio de Janeiro & Rio de Janeiro & $\mathrm{C}^{1}$ \\
\hline 2 & Região Norte e Noroeste Fluminense & Região Metropolitana & $\mathrm{NC}$ \\
\hline
\end{tabular}




\begin{tabular}{|c|c|c|c|}
\hline 3 & Região Metropolitana & Região Serrana & NC \\
\hline 4 & Baixadas Litorâneas $^{2}$ & Baixadas Litorâneas & C \\
\hline 5 & Região Serrana & $\begin{array}{c}\text { Costa Verde, Médio Paraíba e Centro- } \\
\text { Sul Fluminense }\end{array}$ & NC \\
\hline 6 & $\begin{array}{c}\text { Costa Verde, Médio Paraíba e Centro- } \\
\text { Sul Fluminense }\end{array}$ & $\begin{array}{c}\text { Região Norte e Noroeste Fluminense } \\
\text { NC }\end{array}$ \\
\hline
\end{tabular}

Fonte: Elaboração Própria

Nota 1: NC=Não Corresponde; $\mathrm{C}=$ Corresponde

Nota 2: Em Itálico: Regiões cujos municípios não passaram pelos filtros aplicados

\subsubsection{TI: Suporte Técnico, Tratamento de Dados e Portais}

No que concerne à categoria "TI - Suporte Técnico, Tratamento de Dados e Portais", o cruzamento evidenciou novamente uma correspondência entre oferta e demanda na capital do estado, líder em ambas as dimensões. Apesar de ter se observado também correspondências nas Baixadas Litorâneas e na Região Norte e Noroeste Fluminense, as mesmas não possuem relevância uma vez que tais regiões não apresentaram concentrações econômicas. $\mathrm{O}$ dado que merece atenção nesta categoria é o descompasso entre oferta e demanda na Região Serrana, que ocupa a segunda posição na demanda por capacitação, mas está atrás da Região Metropolitana no que tange à oferta de formação. O Quadro 9 apresenta o cruzamento completo.

\section{Quadro 5: Cruzamento entre Oferta e Demanda na Categoria "TI - Suporte Técnico, Tratamento de Dados} e Portais"

\begin{tabular}{|c|c|c|c|}
\hline \multicolumn{4}{|c|}{ TI: Suporte Técnico, Tratamento de Dados e Portais } \\
\hline Ordem & Demanda & Oferta & Cruzamento \\
\hline 1 & Rio de Janeiro & Rio de Janeiro & $\mathrm{C}^{\mathbf{1}}$ \\
\hline 2 & Região Serrana & Região Metropolitana \\
\hline 3 & $\begin{array}{c}\text { Costa Verde, Médio Paraíba e Centro-Sul } \\
\text { Fluminense }\end{array}$ & Região Serrana & $\mathrm{NC}$ \\
\hline 4 & Baixadas Litorâneas & Baixadas Litorâneas & $\mathrm{C}$ \\
\hline 5 & Região Metropolitana & Costa Verde, Médio Paraíba e Centro-Sul & $\mathrm{NC}$ \\
\hline 6 & Região Norte e Noroeste Fluminense & $\mathrm{C}$ \\
\hline
\end{tabular}

Fonte: Elaboração Própria

Nota 1: NC=Não Corresponde; $\mathrm{C}=$ Corresponde

Nota 2: Em Itálico: Regiões cujos municípios não passaram pelos filtros aplicados

\subsubsection{Gestão}

No que se refere à categoria "Gestão", a única concentração econômica encontrada também é a que possui a maior disponibilidade de oferta de formação, neste caso a cidade do Rio de Janeiro. Observa-se, portanto, uma correspondência entre oferta e demanda como explicitado no Quadro 10.

Quadro 6: Cruzamento entre Oferta e Demanda na Categoria "Gestão"

\begin{tabular}{|c|c|c|c|}
\hline \multicolumn{4}{|c|}{ Gestão } \\
\hline Ordem & Demanda & Oferta & Cruzamento \\
\hline 1 & Rio de Janeiro & Rio de Janeiro & $\mathrm{C}^{1}$ \\
\hline 2 & Baixadas Litorâneas $^{2}$ & Região Metropolitana & $\mathrm{NC}$ \\
\hline 3 & Região Norte e Noroeste Fluminense & $\begin{array}{c}\text { Costa Verde, Médio Paraíba e Centro-Sul } \\
\text { Fluminense } \\
\end{array}$ & $\mathrm{NC}$ \\
\hline 4 & Região Metropolitana & Região Serrana & $\mathrm{NC}$ \\
\hline 5 & $\begin{array}{c}\text { Costa Verde, Médio Paraíba e Centro-Sul } \\
\text { Fluminense }\end{array}$ & Região Norte e Noroeste Fluminense & $\mathrm{NC}$ \\
\hline 6 & Região Serrana & Baixadas Litorâneas & $\mathrm{NC}$ \\
\hline
\end{tabular}

Fonte: Elaboração Própria

Nota 1: NC=Não Corresponde; $\mathrm{C}=$ Corresponde

Nota 2: Em Itálico Regiões cujos municípios não passaram pelos filtros aplicados 


\subsubsection{Arquitetura e Engenharia}

Nesta categoria observa-se uma perfeita correspondência entre oferta e demanda na capital, na Região Metropolitana e na Região Costa Verde, Médio Paraíba e Centro-Sul Fluminense, enquanto que no interior há um evidente descompasso, como observado no quadro 11.

Quadro 7: Cruzamento entre Oferta e Demanda na Categoria “Arquitetura e Engenharia"

\begin{tabular}{|c|c|c|c|}
\hline \multicolumn{3}{|c|}{ Arquitetura e Engenharia } \\
\hline Ordem & Demanda & Oferta & Cruzamento \\
\hline 1 & Rio de Janeiro & Região Metropolitana & C \\
\hline 2 & Região Metropolitana & Cluminense & C \\
\hline 3 & Costa Verde, Médio Paraíba e Centro-Sul & Costa Verde, Médio Paraíba e Centro-Sul & NCense \\
\hline 4 & Baixadas Litorâneas ${ }^{2}$ & Região Norte e Noroeste Fluminense & NC \\
\hline 5 & Região Norte e Noroeste Fluminense & Região Serrana & NC \\
\hline 6 & Região Serrana & Baixadas Litorâneas & NC \\
\hline
\end{tabular}

Fonte: Elaboração Própria

Nota 1: NC=Não Corresponde; $\mathrm{C}=$ Corresponde

Nota 2: Em Itálico: Regiões cujos municípios não passaram pelos filtros aplicados

\subsubsection{Pesquisa e Desenvolvimento}

Quanto à categoria "Pesquisa e Desenvolvimento" observa-se um descasamento entre oferta e demanda. A única concentração econômica apontada na pesquisa está no município do Rio de Janeiro. No entanto, o levantamento da oferta por capacitação demonstrou que a mesma está concentrada no entorno metropolitano. O Quadro 12 apresenta o cruzamento completo.

Quadro 8: Cruzamento entre Oferta e Demanda na Categoria "Pesquisa e Desenvolvimento"

\begin{tabular}{|c|c|c|c|}
\hline \multicolumn{4}{|c|}{ Pesquisa e Desenvolvimento } \\
\hline Ordem & Demanda & Região Metropolitana & Cruzamento \\
\hline 1 & Rio de Janeiro & Rio de Janeiro & NC \\
\hline 2 & $\begin{array}{c}\text { Costa Verde, Médio Paraíba e Centro-Sul } \\
\text { Fluminense }\end{array}$ & Região Serrana & NC \\
\hline 3 & Região Metropolitana & Região Norte e Noroeste Fluminense & NC \\
\hline 4 & Baixadas Litorâneas & Costa Verde, Médio Paraíba e Centro-Sul & NC \\
\hline 5 & Região Norte e Noroeste Fluminense & NC \\
\hline 6 & Região Serrana & Baixadas Litorâneas & NC \\
\hline
\end{tabular}

Fonte: Elaboração Própria

Nota 1: $\mathrm{NC}=$ Não Corresponde; $\mathrm{C}=$ Corresponde

Nota 2: Em Itálico: Regiões cujos municípios não passaram pelos filtros aplicados

\section{CONSIDERAÇÕES FINAIS}

O objetivo deste artigo foi realizar um diagnóstico das condições de capacitação para Serviços Empresariais Intensivos em Conhecimento relevantes para a economia fluminense e refletir de que forma estas condições de capacitação afetam as possibilidades de desenvolvimento de inovações.

Os resultados indicam uma expressiva concentração de demanda e oferta de KIBS na capital e na Região Metropolitana do Estado do Rio de Janeiro. Este achado era de se esperar, pois como sugerido pela literatura os KIBS são coprodutores de conhecimento e como tal tendem a se localizar nas regiões mais desenvolvidas (Guimarães e Meirelles, 2014). No caso do ERJ, a capital e a Região Metropolitana representam quase 2/3 do PIB estadual, concentrando $70 \%$ dos estabelecimentos e 3/4 dos empregos formais do Estado (Santos, 2016).

Um resultado interessante é a presença da Região Norte Fluminense na demanda de serviços de TI. Este achado provavelmente se deve à localização das atividades relacionadas ao complexo de Petróleo e Gás nesta região. $O$ fato de que a região possui poucos egressos de cursos superiores nas formações 
correspondentes indica a necessidade de políticas de fomento às universidades locais para consolidar a vocação da região nesta atividade.

Outro resultado interessante é a presença da Região Centro-Sul Fluminense na demanda de serviços de engenharia. Este achado provavelmente se deve à localização das atividades relacionadas ao complexo automobilístico e à indústria siderúrgica nesta Região. Neste caso, a Região dispõe de capacitação com potencial para atender à demanda.

Os resultados indicaram também que vários municípios do interior do estado apresentam concentrações de serviços empresariais, porém o emprego nestas concentrações é de baixa qualificação. Cabe investigar o perfil da qualificação nas concentrações eliminadas para verificar a possibilidade de políticas de apoio às empresas destes municípios centradas em capacitação.

As condições de capacitação mapeadas sugerem que há mais possibilidades de desenvolvimento de inovações induzidas por KIBS na capital e na Região Metropolitana. Entretanto, apostar no desenvolvimento de inovações nestes municípios significa reforçar a fragilidade da estrutura produtiva fluminense e a concentração espacial de empregos que o ERJ já apresenta. Uma política de inovação que vise contribuir para a diversificação da economia fluminense deveria considerar o reforço de ambientes de inovação no interior do ERJ. Santos (2016) mostrou que as incubadoras do interior do Estado - que são parte importante dos ambientes de inovação - sofrem com base de conhecimentos reduzida, oferta limitada de mão de obra qualificada, baixa densidade de firmas dinâmicas, e distância dos principais centros de decisão.

Assim, o Estado do Rio de Janeiro apresenta concentrações geográficas de KIBS e tem cursos de ensino superior capazes de suprir a demanda de KIBS, porém a concentração destes serviços na capital e na região metropolitana limita as possibilidades de promoção destes serviços enquanto instrumento de diversificação da economia fluminense.

\section{REFERÊNCIAS BIBLIOGRÁFICAS}

ABDAL, A.; TORRES-FREIRE, C.; CALLIL, V. Rethinking sectoral typologies: A classification of activity according to knowledge and technological intensity. Industrial Marketing Management, v. 13, p. 232-241, 2016.

AMARA, N.; LANDRY, R.; TRAORÉ, N. Managing the protection of innovations in knowledge-intensive business services. Research Policy, v. 37, n. 9, p. 1530-1547, 2008.

ARBACHE, J. Serviços e competitividade industrial no Brasil. Confederação Nacional da Indústria - Brasília: Confederação Nacional da Indústria, 2014.

MACHADO, A.; ARBACHE, J.; MOREIRA, R. Nota Técnica - Classificações das Atividades de Serviços. Publicado no Blog Economia de Serviços. Disponível em: https://economiadeservicos.com/wpcontent/uploads/2015/09/Nota-T\%C3\%A9cnica-Classifica\%C3\%A7\%C3\%B5es.pdf

BETTENCOURT, L.; OSTROM, A.; BROWN, S.; ROUNDTREE, R. Client co-production in knowledgeintensive business services. California Management Review, v. 44, n. 4, 2002.

BRITTO, J; CASSIOLATO, J.E; MARCELLINO, I. S. Especialização produtiva e dinamismo inovativo da indústria fluminense: desafios e potencialidades para o desenvolvimento regional. In: Osorio, M.; Melo, L.M.; Versiani, M.H; Werneck, M.L. (orgs). Uma agenda para o Rio de Janeiro: Estratégias e Políticas Públicas para o Desenvolvimento Socioeconômico. Rio de Janeiro: FGV: 2015.

CALABRIA, P.; BERNARDES, R.; VARGAS, E.; PINHANEZ, C. A ciência da inovação em serviços: estudo exploratório sobre os interesses e prioridades para uma agenda de pesquisa no Brasil. Revista de Administração e Inovação, São Paulo, v. 10, n.4, p.110-135, out./dez. 2013.

CZARNITZKI, D.; SPIELKAMP, A. Business services in Germany: bridges for innovation. Service Industries Journal, v. 23, n. 2, p. 1-30, 2003. 
DEN HERTOG, P. Knowledge-Intensive Business Services as Co-Producers of Innovation. International Journal of Innovation Management, v. 4, n. 4, p. 491, 2000.

EICHENGREEN, B.; GUPTA, P. The two waves of service sector growth. National Bureau of Economic Research. Working Paper, n. 14968, Cambridge, 2009.

FAPERJ - FUNDAÇÃO DE AMPARO À PESQUISA DO ESTADO DO RIO DE JANEIRO. Mapa da ciência. Rio de Janeiro: FAPERJ, 2014.

FIRJAN - FEDERAÇÃO DAS INDÚSTRIAS DO ESTADO DO RIO DE JANEIRO. Visões de futuro: Potencialidades e desafios para o Estado do Rio de Janeiro nos próximos 15 anos. FIRJAN, Rio de Janeiro, 2014.

GRIMSHAW, D.; MIOZZO, M. Knowledge Intensive Business Services: Understanding Organizational Forms And The Role Of Country Institutions. In: GRIMSHAW, D.; MIOZZO, M. (Eds.), Knowledge intensivebusiness services: Organizational forms and national institutions. Cheltenham: Edward Elgar, 2006.

GUIMARÃES, J.G.A; MEIRELLES D.S. Caracterização e localização das empresas de serviços tecnológicos intensivos em conhecimento no Brasil. Gestão e Produção v.21 n.3, p.503-519, 2014

GUIMARÃES, S. Empreendedorismo intensivo em conhecimento no Brasil. Caderno CRH. vol. 24, n.63, pp.575592, 2011.

HASENCLEVER, L.; PARANHOS, J.; TORRES, R. Desempenho Econômico do Rio de Janeiro: Trajetórias Passadas e Perspectivas Futuras. In: DADOS - Revista de Ciências Sociais, Rio de Janeiro, vol. 55, n. 3, pp. 681 a $711,2012$.

HILL, T. On goods and services. Review of Income and Wealth; 23(4):315-38, 1977.

KON, A. Sobre as atividades de Serviços: Revendo conceitos e tipologias. Revista de Economia Política, vol. 19, $\mathrm{n}^{\circ} 2,(74), 1999$.

. (Org.). Pesquisa em economia industrial, trabalho e tecnologia. São Paulo: Fapesp/PUC-SP, 2004.

KUBOTA, C. L. A inovação tecnológica das firmas de serviços no Brasil. In: DE NEGRI, J. A.; KUBOTA, L. C. (Orgs.). Estrutura e Dinâmica do Setor de Serviços no Brasil. Brasília: IPEA, pp. 35-72, 2006.

. As KIBS e a inovação tecnológica das firmas de serviços. Economia e Sociedade, Campinas, v. 18, n. 2 (36), p. 349-369, ago. 2009.

LA ROVERE, R.; PARANHOS, J. Os investimentos no estado do Rio de Janeiro e seus efeitos sobre as micro e pequenas empresas. Relatório Técnico elaborado para o Observatório de Micro e Pequenas Empresas do IETS. Rio de Janeiro:SEBRAE/RJ, 2011. Disponível em http://arquivopdf.sebrae.com.br/uf/rio-de-janeiro/sebrae-no-rio-dejaneiro/estudos-e-pesquisas/estudo.pdf

LA ROVERE, R. (Coord.) Condições de capacitação empresarial e os ambientes de inovação no Estado do Rio de Janeiro. Relatório Técnico para a FAPERJ (Edital 28/2012). Rio de Janeiro: IE/UFRJ, 2015.

MARCELLINO, I. O Complexo Produtivo de $P \& G$ como vetor para o fortalecimento do SRI Fluminense: uma análise de determinantes estruturais e organizacionais. Dissertação de mestrado defendida no programa de pósgraduação em economia da UFF, 2014.

METCALFE, S.; MILES, I. Services: Invisible Innovators. Paper presented at CSLS Conference on Service Sector Productivity and the Productivity Paradox April 11 - 12, Chateau Laurier Hotel Ottawa, Canada, 1997.

MILES, I. Knowledge intensive business services: prospects and policies. Foresight - The Journal of Future Studies, Strategic Thinking and Policy, 7(6):39-63, 2005.

MILES, I.; KASTRINOS, N.; FLANAGAN, K.; BILDERBEEK, R.; DEN HERTOG, P. Knowledge-intensive business services: users, carriers and sources of innovation. European Innovation Monitoring Systems. EIMS Publication $n^{\circ}$ 15. Innovation Programme, DGXIII, Luxembourg. 1995. 
MULLER, E.; DOLOREUX, D. What we should know about knowledge-intensive business services. Technology in Society, v. 31, n. 1, p. 64-72, 2009.

What we should know about Knowledge-Intensive Business Services. Industrial Marketing Management, v. 31, p. 64-72, 2016.

NATAL, J. Inflexão econômica e dinâmica espacial pós-1996 no Estado do Rio de Janeiro. In: Nova Economia, Belo Horizonte, 14 (3) pp. 71-90, setembro-dezembro/2004.

NATIONAL SCIENCE BOARD. Science and Engineering Indicators 2010. Arlington, VA: jan. 2008.

PORTO, G.; KANNEBLEY JR., S.; DIAS, A.; RADAELLI, V. O Sistema Estadual de Inovação do estado do Rio de Janeiro: uma contribuição ao diálogo de políticas entre o governo do Estado do Rio de Janeiro e o Banco Interamericano de Desenvolvimento. BID, 2012.

SANTOS, A. Economia fluminense: Superando a perda de dinamismo? In: Revista Rio de Janeiro, n. 8, p. 31-58, set./dez. 2002.

SANTOS, G.O. Alinhamento das incubadoras de empresas ao contexto regional no Estado do Rio de Janeiro: uma comparação entre metrópole e interior. Dissertação (Mestrado em Políticas Públicas, Estratégias e Desenvolvimento) - Instituto de Economia, Universidade Federal do Rio de Janeiro, 2016. Disponível em: http://www.ie.ufrj.br/images/pos-graducao/pped/dissertacoes_e_teses/Guilherme_Santos.pdf

SCHMITT, M. T.; TEZA, P.; DOROW, P. F.; DANDOLINI, G. A.; ABREU, A. KIBS como agentes de inovação: mapeamento e análise da literatura. Paper apresentado no XXXII Encontro Nacional de Engenharia de Produção, Bento Gonçalves, RS, Brasil, 2012.

SIMMIE, J.; STRAMBACH, S. The contribution of KIBS to innovation in cities: an evolutionary and institutional perspective. Journal of Knowledge Management, v. 10, n. 5, p. 26-40, 2006.

SOBRAL, B. Metrópole do Rio e Projeto Nacional: Uma estratégia de desenvolvimento a partir de complexos e centralidades no território. Ed. Garamond, Rio de Janeiro, 2012.

. A Falácia da "inflexão econômica positiva": algumas características da desindustrialização fluminense e do "vazio produtivo" em sua periferia metropolitana. In: Cadernos do Desenvolvimento Fluminense, n. 1, Rio de Janeiro, fevereiro, 2013.

A evidência da estrutura produtiva oca: o Estado do Rio de Janeiro como um dos epicentros da desindustrialização nacional. In: NETO, A. M.; CASTRO, C. N.; BRANDÃO, C. A. (orgs.) Desenvolvimento regional no Brasil: políticas, estratégias e perspectivas. Rio de Janeiro: IPEA, 2017.

TORRES-FREIRE, C. Um estudo sobre os serviços intensivos em conhecimento no Brasil. In: DE NEGRI, J. A.; KUBOTA, L. C (Orgs.). Estrutura e Dinâmica do Setor de Serviços no Brasil. Brasília: IPEA, pp.107-132, 2006.

WENHONG, Y.; MIN, Y. The policy to promote the innovative development of knowledge intensive business services. International Journal of Business \& Management, v. 5, n. 11, p. 190-194, 2010. 